\title{
Assessment of seismic risk and reliability of road network
}

\author{
Salvatore Cafiso \\ University of Catania \\ Italy
}

\section{Introduction}

Essential services for road users as well as for every kind of human activity are strongly dependent from road network that is considered a "lifeline" as one of the essential linear infrastructures for human life. When a catastrophic event strikes a wide area, it is necessary that the infrastructure system is designed with a high redundancy and/or low risk of failure to maintain network function to give access for the rescue service.

In the case of damage produced by seismic events, the effects of an interruption to the road network and the consequent reduction of what remains available profoundly affect the overall performance of the system (increasing travelling time, distance and costs).

The road network must be reliable, that is, it must (Wakabayashi, Idia, 1992) “.... provide a safe and not fluctuating service for the traffic and offer the users alternative routes, even when some parts of the system are not available due to road accidents, maintenance or natural disasters".

If network Reliability is able to measure the ability of the system to maintain its performance due to the vulnerability to suffer damages of some of its components, Risk assessment is able to consider other aspects in addition to the overall functionality of the network system such as the consequences in terms of victims that can derive from the reduction of its functionality.

In the chapter a comprehensive methodology framework for the evaluation of the seismic risk and reliability of rural road networks will be presented. These original methodologies make it possible to identify beforehand critical parts of the road network as regards to possible structural damage and the importance of the connection related to the number of inhabitants that could suffer a delay in the emergency services. The analyses were carried out considering bridges as the "weak" element of the road infrastructure in case of seismic events, but the procedure could also be applied to different types of element (trenches, embankments, culverts, etc).

The methodology has been designed for applications based on Geographic Information System (GIS). With reference to different seismic emergency scenarios (road network, seismic intensity, O/D routes), case studies are presented to highlight the possibility of a preventive estimation of towns and links that present different levels of Risk. 


\section{Risk assessment}

Risk assessment aims to define a measure of the risk. Since risk management is subject to large costs and variable benefits, proper risk assessment and management are crucial to make successful actions.

Risk can be defined as: the combination of the likelihood of an occurrence of a hazardous event and the severity of the consequences (human, social and economical losses) that can be caused by the event. Therefore, if the measurement of uncertainty refers only to the probabilities of the event occurrence, the measure of risk requires to carry out both the probability for outcomes and the related losses.

Based on this definition, risk assessment of road network can be carried out as the product of three independent factors (Cafiso et al. 2005, Cafiso et al. 2008, Cafiso 2009):

1) Exposure, given by the number of people (and/or goods) that can be damaged by the event.

2) Hazard, linked to the probability that in a certain place there will be an event of a certain intensity with a given return time;

3) Vulnerability, which defines the propensity of an infrastructural element to undergo damage during the event.

In the following a complete definition of each term and the methodology to measure it will be provided.

\subsection{Exposure}

Seismic exposure represents the extension, the quantity and quality of the various anthropic elements that make up the territorial context (population, buildings, infrastructure, etc.) whose conditions and operation could be damaged by a seismic event. The population is the main category at risk and the potential number of injured or dead people is considered as a measure of exposure.

In a seismic risk assessment it is fundamental to consider the "direct exposure" of the users of the transportation network beyond the "classical" one of the resident population of the urban buildings. In fact, specially in urban area, on road infrastructures during much of the day a great number of people are exposed to risk as well as those who are inside buildings. It should be remembered that in the Loma Prieta earthquake (USA, 17-10-1989, Magnitude $\mathrm{M}_{\mathrm{SW}}$ 7.1) the collapse of the viaducts of the busy Cypress Street, in the City of Oakland, caused the highest number of fatalities (42 on a total of 56 deaths) (Figure 1).
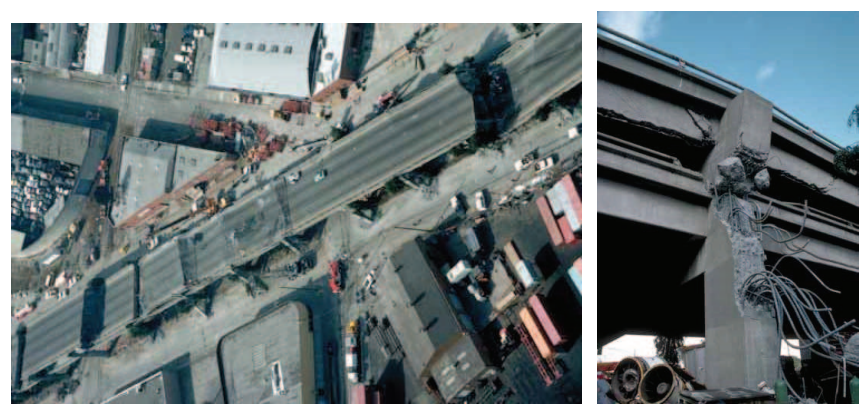

Fig. 1. Loma Prieta, sections of the Cypress viaduct (H.G. Wilshire, U.S. Geological Survey) 
The "direct exposure" can be related to the number of users present along the infrastructure during the event or to the property value or to the mission of the element in the transportation system. The expected vehicle density (vehicles per unit length of road) can be used as measure of exposure.

Table 1 shows threshold direct exposure levels used in CAPTA (NCHRP report 525, 2009) to determine if a transportation asset exceeds the threshold and will be included in further analysis as a high-consequence asset. The distinct differentiation between potentially exposed populations, property, and mission is highlighted within the equation box.

\begin{tabular}{|c|c|c|c|}
\hline Asset & $\begin{array}{l}\text { Potentially Exposed } \\
\text { Population Equation }\end{array}$ & $\begin{array}{l}\text { Property } \\
\text { Equation }\end{array}$ & Mission Equation \\
\hline Road Bridges & $\begin{array}{l}\text { Separated into primary } \\
\text { direction and secondary } \\
\text { direction - for each, if } \\
\text { vehicles/lane }>2400 \text {, assume } \\
40 \quad \text { vehicles } / 1000 \\
\text { Otherwise assume } \\
\text { vehicles } / 1000 \mathrm{ft}\end{array}$ & $\$ 20,000 /$ feet & $\begin{array}{l}\text { (ADT) } \times \text { (detour length) } 75 \text { th, } \\
\text { 85th, } 95 \text { th percentile thresholds } \\
\text { relative to typical bridge } \\
\text { inventory (Example is based on } \\
\text { the National Bridge Inventory) }\end{array}$ \\
\hline Road Tunnels & $\begin{array}{l}\text { Separated into primary } \\
\text { direction and secondary } \\
\text { direction - for each, il } \\
\text { vehicles/lane }>2400 \text {, assume } \\
40 \quad \text { vehicles } / 1000 \quad \mathrm{ft} . \\
\text { Otherwisw assume } \\
\text { vehicles } / 1000 \mathrm{ft}\end{array}$ & $\$ 100,000 /$ feet & User input for criticality \\
\hline $\begin{array}{l}\text { Transit/Rail } \\
\text { Station }\end{array}$ & $\begin{array}{l}4 \times \text { (maximum capacity of rail } \\
\text { cars) }\end{array}$ & $\begin{array}{l}\text { Below ground } \\
=\text { critical }\end{array}$ & $\begin{array}{l}\text { User input if transfer station is } \\
\text { critical }\end{array}$ \\
\hline $\begin{array}{c}\text { Transit/Rail } \\
\text { Bridge }\end{array}$ & $\begin{array}{l}2 \times \text { (maximum capacity of rail } \\
\text { cars) }\end{array}$ & $\$ 15,600 /$ feet & $\begin{array}{l}\text { User input percentage of } \\
\text { ridership that regularly use this } \\
\text { transit/rail transportation asset }\end{array}$ \\
\hline $\begin{array}{l}\text { Transit/Rail } \\
\text { Tunnel }\end{array}$ & $\begin{array}{l}2 \times \text { (maximum capacity of rail } \\
\text { cars) }\end{array}$ & $\$ 40,000 /$ feet & $\begin{array}{l}\text { User input percentage of } \\
\text { ridership that regularly use this } \\
\text { transit/rail transportation asset }\end{array}$ \\
\hline
\end{tabular}

Table 1. Threshold consequence determination (NCHRP REPORT 525, 2009)

In the emergency phases that follow a seismic event, the transportation network has the task of making assistance accessible to the stricken area so that aids can be quick and efficient. If road infrastructure efficiency has been compromised due to the effects of the quake, to reach the stricken areas would be impossible or really slow and difficult. Many strong earthquakes have tragically shown the essential role that transportation network has to provide timely emergency services after a seismic event. In the Kobe earthquake (Japan, 1701-1995, Magnitude $\mathrm{M}_{\mathrm{SW}}$ 6.92) interruption of the access routes prevented emergency services from reaching the devastated areas for many hours (Figure 2). As consequence, damage from fires indirectly caused by the quake determined consequences comparable to that caused directly by the quake (totally 5.500 fatalities).

Based on these considerations an original definition of "indirect exposure" on single stretches of the road network can be defined in relation to the number of people who would experience delays in the arrival of emergency services due to an interruption of that given 
stretch of the network. The analysis of indirect seismic exposure consists in a study of estimations of damage or injury to the population that can result from a road network or of a part of it that does not function correctly. It is, obviously, a study of exposure because the object is the analysis of damage or injury suffered by people as an indirect consequence of the bad efficiency of road networks after the event.
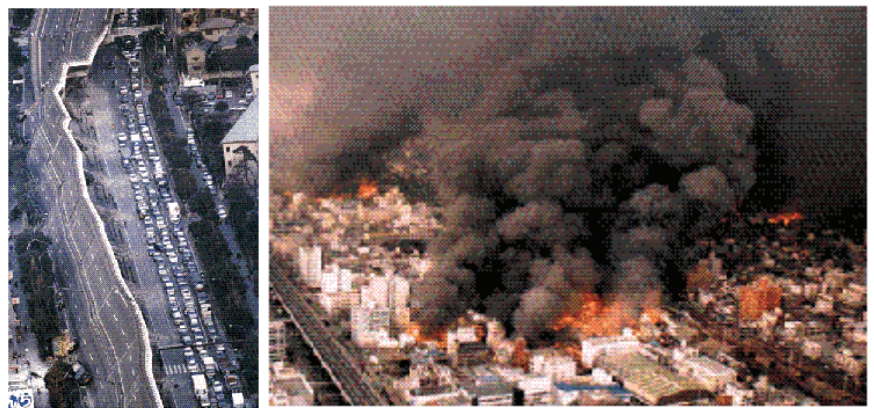

Fig. 2. Kobe earthquake, interrupted access route and fires caused by the quake

The level of damage caused by this kind of situation is different according to the dimensions and characteristics of the city that has been hit by the quake. Each town, in fact, has to be considered as a generator of demand for assistance that is proportional to the resident population. Therefore, indirect exposure of a stretch of the road network increases with the growth of the expected number of resident population stroked by the earthquake in the towns linked to it.

The road system as to be analyzed as a network composed by links (i.e. the road stretches) between two nodes representing the intersections. The assignation of indirect exposure to a link of the network follows the following three steps:

1) to each town (Di) destination of the emergency services, an "direct exposure" value is assigned equal to the number of its inhabitants multiplied by the 'index of seismic risk' ranging between 0 to 0.8 that in Italy is defined proportionally to the percentage of expected losses after an earthquake (Ord.P.C.M. n. 2788 del 12/06/1998);

2) defining the route from the origin $(\mathrm{O})$ to the destination $(\mathrm{Di})$, to each of the links along this route, an "indirect exposure" (Ei) is assigned equal to the direct exposure value of the town of destination.

3) the overall indirect exposure of each link of the road network is carried out as sum of the Ei values related to all the destinations (Di) using that link in the O/Di routes.

\subsection{Hazard}

Seismic hazard defines the probability of occurrence of a seismic event of certain intensity, in a given area and in a given period of time. The evaluation of seismic hazard of an area is based on the study of historic seismology and on the analysis of the geological seismologic and seismogenetic characteristics of the site.

The historical studies are aimed at the definition of the principal geophysical characteristics (epicenter, magnitude, ground acceleration etc.) of seismic events that have struck in the past the area under examination, in such a way as to predict the effects of earthquakes expected for different return times in terms of horizontal force, acceleration, etc. 
Peak Ground Acceleration (PGA ) is used as the seismic hazard measurement parameter. In Italy, this parameter is provided by the National Institute of Geophysics and Volcanology (I.N.G.V.) in terms of PGA with an $81 \%, 63 \%, 50 \%, 39 \%, 22 \%, 10 \%, 5 \%, 2 \%$ probability of exceeding this in 50 years, corresponding to a return time period of 30,50,72, 100, 200, 475, 975 and 2475 years.

\subsection{Vulnerability}

Seismic vulnerability is defined as the propensity of an element, simple or complex, to suffer damage, collapse or modification during a seismic event. Seismic vulnerability is an intrinsic characteristic of each construction, that is independent from any kind of external factor. For example, the vulnerability of a bridge depends on the construction technologies adopted, on the materials employed, on its structural configuration, on its age, on its state of maintenance, on the quality of the original project and so on. All these factors are independent from the localization of the object and from the probability that a seismic event can take place there, which has been already evaluated in the study of seismic hazard.

To define the vulnerability of a road segment, it should be considered that each stretch could be composed by a series of components (bridges, embankments, trenches, tunnels...) with different vulnerability characteristics and evaluation models not always comparable.

In the following tables (tables 2a-2d) a selection of the principal elements that need to be considered to evaluate the structural vulnerability for each component, is presented (Cafiso et al., 2005).

\begin{tabular}{|l|l|l|}
\hline Element & Min. Vulnerability $\leftarrow$ Max. Vulnerability \\
\hline Design criteria & $\begin{array}{l}\text { Constructed according to seismic } \\
\text { criteria }\end{array}$ & Constructed without seismic criteria \\
\hline Construction type & Continuous structures & Discontinuous structures \\
\hline $\begin{array}{l}\text { Regularity of } \\
\text { geometry } \\
\text { rigidity }\end{array}$ & Regular structures & Irregular structures \\
\hline Pier type & Single & Multiple \\
\hline Abutment height & Low & High \\
\hline $\begin{array}{l}\text { Soil-foundation } \\
\text { system }\end{array}$ & good & Bad and with liquefaction problems \\
\hline $\begin{array}{l}\text { Condition of the } \\
\text { construction }\end{array}$ & Good state of conservation & Bad state of conservation \\
\hline Alignment bearing & $\begin{array}{l}\text { If longitudinal and transversal } \\
\text { movement is allowed and there are } \\
\text { systems to prevent girder fall }\end{array}$ & Simple support \\
\hline $\begin{array}{l}\text { Type of } \\
\text { support }\end{array}$ & Present with seismic criteria & $\begin{array}{l}\text { Present with a short } \\
\text { base }\end{array}$ \\
\hline Expansion joints & None & masonry \\
\hline Building material & steel & Reinforced concrete \\
\hline
\end{tabular}

Table 2a. Factors for the evaluation of seismic vulnerability of bridges and viaducts

If more than one vulnerable component is present on the same network link, to characterise with only one indicator of vulnerability a stretch of road between to nodes, many criteria of aggregation could be used, among which one of the simplest and of immediate application 
consists in giving to the whole stretch the maximum value from among the indicators of structural vulnerability of the components that make it up.

\begin{tabular}{|c|c|c|c|c|}
\hline Element & \multicolumn{4}{|c|}{ Min. Vulnerability $\leftarrow$} \\
\hline Design criteria & \multicolumn{2}{|c|}{$\begin{array}{l}\text { Constructed according to seismic } \\
\text { criteria }\end{array}$} & \multicolumn{2}{|c|}{ Constructed without seismic criteria } \\
\hline Height & \multicolumn{2}{|c|}{ Low } & \multicolumn{2}{|l|}{ High } \\
\hline $\begin{array}{l}\text { Geometrical } \\
\text { condition of the site }\end{array}$ & $\begin{array}{l}\text { Low inclination } \\
\text { of ground }\end{array}$ & \begin{tabular}{|lr} 
& High inclination of \\
ground & with \\
seismic wall
\end{tabular} & $\begin{array}{l}\text { High inclination } \\
\text { of ground with } \\
\text { no seismic wall }\end{array}$ & $\begin{array}{l}\text { High inclination } \\
\text { of ground } \\
\text { without wall }\end{array}$ \\
\hline $\begin{array}{l}\text { Embankment } \\
\text { geometry }\end{array}$ & \multicolumn{2}{|c|}{ Slope inclination $<2 / 3$} & \multicolumn{2}{|c|}{ Slope inclination $>2 / 3$} \\
\hline $\begin{array}{l}\text { Soil support } \\
\text { characteristics }\end{array}$ & \multicolumn{2}{|l|}{ Good } & \multicolumn{2}{|l|}{ Bad } \\
\hline $\begin{array}{l}\text { Condition of the } \\
\text { structure }\end{array}$ & \multicolumn{2}{|c|}{ Good state of conservation } & \multicolumn{2}{|c|}{ Bad state of conservation } \\
\hline Slope protection & \multicolumn{2}{|c|}{ Presence of slope protection } & \multicolumn{2}{|l|}{ No slope protection } \\
\hline
\end{tabular}

Table 2.b. - Factors for the evaluation index of seismic vulnerability of embankments

\begin{tabular}{|c|c|c|c|c|}
\hline Element & \multicolumn{4}{|c|}{ Min. Vulnerability $\leftarrow$} \\
\hline Design criteria & \multicolumn{2}{|c|}{$\begin{array}{l}\text { Constructed according to antiseismic } \\
\text { criteria }\end{array}$} & $\begin{array}{l}\text { Constructed } \\
\text { criteria }\end{array}$ & without antiseismic \\
\hline 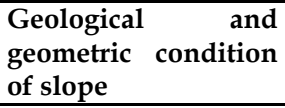 & \multicolumn{2}{|c|}{ Dynamic safety coefficient Fs $\geq 1.3$} & \multicolumn{2}{|c|}{ Dynamic safety coefficient Fs $<1.3$} \\
\hline Length - Height & \multicolumn{2}{|c|}{ Trenches low and short } & \multicolumn{2}{|c|}{ Trenches long and high } \\
\hline Rock fall & Impossible & \multicolumn{2}{|c|}{$\begin{array}{l}\text { Possibility of rock fall with slope } \\
\text { protection }\end{array}$} & \begin{tabular}{|l} 
Possibility of rock fall \\
without \\
protection
\end{tabular} \\
\hline Retaining structures & \multicolumn{3}{|c|}{ built according to antiseismic laws } & ding to antiseismic laws \\
\hline
\end{tabular}

Table 2.c. - Factors for the evaluation index of seismic vulnerability of trenches

\begin{tabular}{|l|l|l|}
\hline Element & Min. Vulnerability $\leftarrow$ & \multicolumn{2}{|c|}{$\rightarrow$ Max. Vulnerability } \\
\hline Design criteria & $\begin{array}{l}\text { Constructed according to } \\
\text { antiseismic criteria }\end{array}$ & $\begin{array}{l}\text { Constructed without antiseismic } \\
\text { criteria }\end{array}$ \\
\hline $\begin{array}{l}\text { Geostructural } \\
\text { condition of the } \\
\text { mass }\end{array}$ & $\begin{array}{l}\text { Good: no earth pressure - absence } \\
\text { of discontinuity }\end{array}$ & $\begin{array}{l}\text { Bad: earth pressure - presence of } \\
\text { landslides and discontinuities }\end{array}$ \\
\hline Deformation joint & Presence of deformation joints & Absence of deformation joints \\
\hline Location & Deep tunnel & Superficial tunnel \\
\hline Section area & Small & Large \\
\hline Section type & Closed section & Open section \\
\hline $\begin{array}{l}\text { Condition of the } \\
\text { structure }\end{array}$ & Good state of conservation & Bad state of conservation \\
\hline
\end{tabular}

Table 2.d. - Factors for the evaluation index of seismic vulnerability of tunnels 
Therefore, basing on experience acquired after a strong Earthquake, a first level macro analysis of large road networks can be conducted considering the vulnerability of only bridges as the weak road structural element when an earthquake strikes (Figure 3).

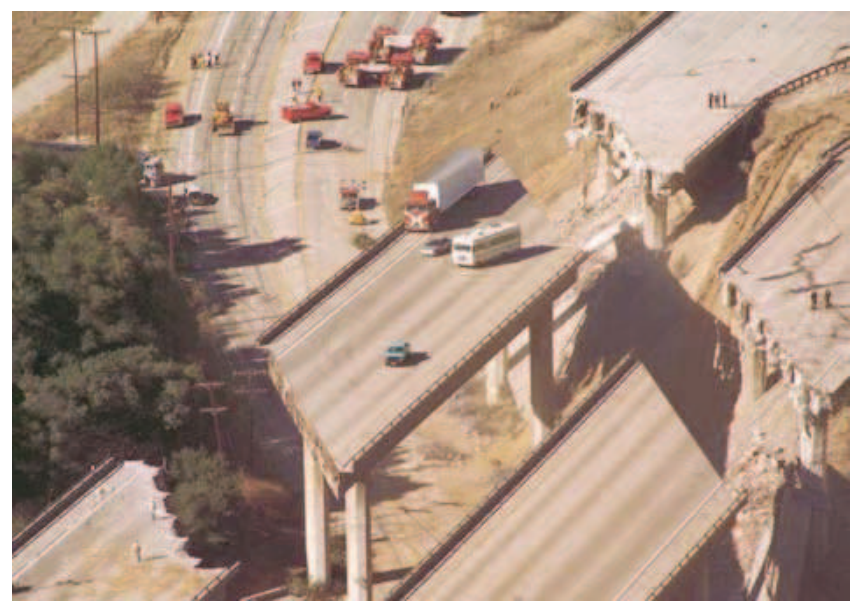

Fig. 3. Example of bridge collapse after an earthquake

To evaluate the seismic vulnerability of the bridges forming part of a road network, a model (Buckle, Kim, 1995) was selected from the literature because it is particularly effective for the proposed approach:

- it minimizes the arbitrariness of subjective judgement;

- all the parameters indicated by the procedure can be easily identified in the bridges of the area under investigation;

- the way of determining damage as a product of hazard and vulnerability is suitable for the risk evaluation method adopted;

- the model provides a numerical damage index.

In the model (Buckle, Kim, 1995), the level of vulnerability (V) is obtained using a linear regression of the damage indicators recorded during seismic events and related to evaluation parameters present in the model:

$$
\mathrm{V}=\Sigma \mathrm{i} \beta \mathrm{i} \times \mathrm{Xi}
$$

where: $\mathrm{Xi}(\mathrm{i}=1, \ldots, 12)$ is the value assumed by the model parameters (Intensity of Peak Ground Acceleration, Design Specification, Type of Superstructure, Shape of Superstructure, Internal Hinge, Type of Pier, Type of Foundation, Material of Substructure, Irregularity in Geometry or in Stiffness, Site Condition, Effect of Liquefaction, Seat Lenght); $\beta \mathrm{i}$ is the weighting factors for each attribute.

\subsection{Damage}

Once the vulnerability (V) and the Hazard (PGA) are defined, it is possible to obtain the damage index for each bridge by means of the following relation: 


$$
\mathrm{D}=\mathrm{XPGA} \times \mathrm{V}
$$

where XPGA is the hazard index assuming the values shown in Table 3.

Table 3. hazard index XPGA

\begin{tabular}{|l|l|}
\hline PGA & XPGA \\
\hline PGA $<0,1 \mathrm{~g}$ & 1 \\
\hline $0,1 \mathrm{~g}<$ PGA $<0,2 \mathrm{~g}$ & 2 \\
\hline $0,2 \mathrm{~g}<$ PGA $<0,3 \mathrm{~g}$ & 3 \\
\hline PGA $>0,3 \mathrm{~g}$ & 4 \\
\hline
\end{tabular}

From equations (1) and (2), the damage D can assume values of between 0 and $9(0=$ no damage, $9=$ maximum damage). Increasing the bridge damage a reduction in the residual traffic capacity (transitability) of the link can be expected. Usually, for low level of damage (only pavement cracking) without structural failure a low speed traffic can be permitted, for medium level of damage (large cracking, join fault) without structural collapse a limited and controlled traffic (only emergencies services) can be permitted, for high damage (deck unseating) till to the collapse of the structure, traffic is not permitted. Therefore, the loss of transitability Index, ranging from 0 to $10(0=$ no traffic limitation, $10=$ traffic not permitted $)$, is associated to the level of damage with the relation shown in figure 4 .

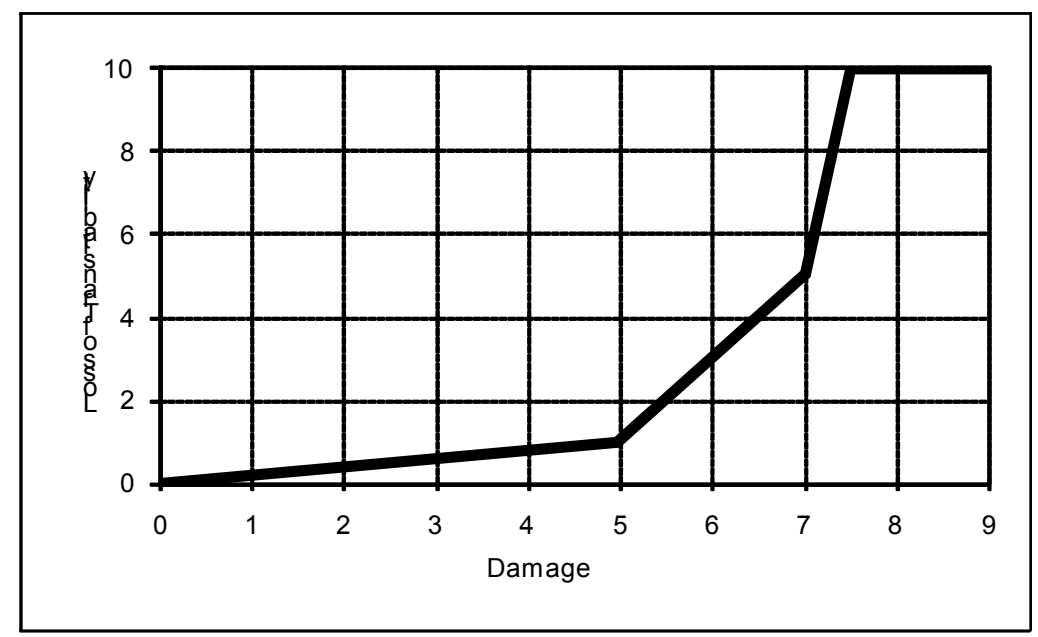

Fig. 4. damage Vs. loss of transitability index $\operatorname{Tr}$

\subsection{Risk}

The risk factor is associated to the access of emergency services to the towns after an earthquake. Therefore, the road network risk assessment can be defined by associating the Damage (Hazard x Vulnerability) and Exposure factors to the links of the road network. 
The procedure comprises the following 5 steps (Cafiso et al, 2008) which refer to different phases of the process and different items of the network system:

Step 1 -Hazard and Vulnerability (item: bridge)

To each bridge in the road network values of vulnerability (V) and XPGA are associated depending to the structural features of the bridge (equation 1) and to the seismic scenario expected in the location of the element (Table 3).

For each bridge an index of Damage is calculated as product of Hazard and Vulnerability (equation 2). Moreover, the loss of Transitability index can be associated to damage (figure 4).

Step 2 - damage and Loss of Transitability (item: link)

When dealing with road links where there are no bridges or overpasses then both Damage and Loss of Transitability were taken as being equal to 0 . For those stretches where there is one bridge or overpass the Damage and Loss of Transitability indexes were assigned on the basis of values carried out in step 1. Finally, if there are more than one bridge and/or overpass then the Damage and Loss of Transitability indexes of the stretch were considered as being equal to the maximum of the values attributed to the different bridges or overpasses.

Step 3 - O/D routes (item: town)

After having defined the origin (O) and the destination (D) in the earthquake scenario, the routes connecting each $\mathrm{O} / \mathrm{D}$ connection can be defined using different criteria (e.g. length, travel time, encountered bridge damage or Loss of Transitability).

Step 4 - Indirect exposure factor (item: link)

An indirect exposure value is assigned to each link of the road network constituting part of the $\mathrm{O} / \mathrm{D}$ route equal to the number of inhabitants in the town of destination multiplied by its seismic risk index (exposure of the town).

Once all the O/Di routes has been identified for all the " $\mathrm{i}$ " destinations, an indirect exposure value can be associated to each link of the network equal to the sum of the values attributed to this link in each of the O/Di.

Therefore, some stretches of the network have a nil exposure, because they have never been used for O/D routes. Others have an exposure value based on a single destination, while those which have been used a number of times in order to reach different destinations have an exposure value equal to the sum of the exposures of the towns for which the stretch is used for that type of route.

Step 5 - Risk evaluation (item: link)

When for each link of the road network the damage value (Step 2) and the indirect exposure (step 4) are carried out, it is possible to obtain the risk value of the link as product of damage and indirect exposure values.

$$
\text { Risk }=\text { Indirect exposure } \times \text { Damage }
$$

\section{Case Study}

Referring to a high seismic-risk area of eastern Sicily (Italy) as case study, it was possible to verify the effectiveness of the proposed procedure. The methodology has been designed for applications based on Geographic Information System (GIS). In particular, implementing the method using the GIS made it possible to draw up maps which identify the most critical stretches for different earthquake scenarios and emergency service origins. 


\subsection{Area of investigation}

The province of Catania has an area of about 3,552 $\mathrm{Km}^{2}$ in which there are 58 towns/cities with an overall population of 1,054,778 inhabitants.

The GIS contains all the data necessary for an analysis of risk and emergency management, organized in shape-files and relational data bases. All the bridges and overpasses present on the road network were positioned within the GIS using 1:10,000 scale maps of the province. 321 bridges and overpasses situated on stretches of the road network within the study zone were localized. For each bridge " $\mathrm{j}$ " a visual inspection was carried out and data were obtained from the Department of Transport and local road Agencies to evaluate the vulnerability parameters $\mathrm{Xji}_{\mathrm{ji}}$ of model (1). As result each bridge localized in the GIS has as attribute a vulnerability index $\mathrm{Vj}$

$$
\mathrm{Vj}=\Sigma \mathrm{i} \beta \mathrm{i} \times \mathrm{Xji}_{\mathrm{j}}
$$

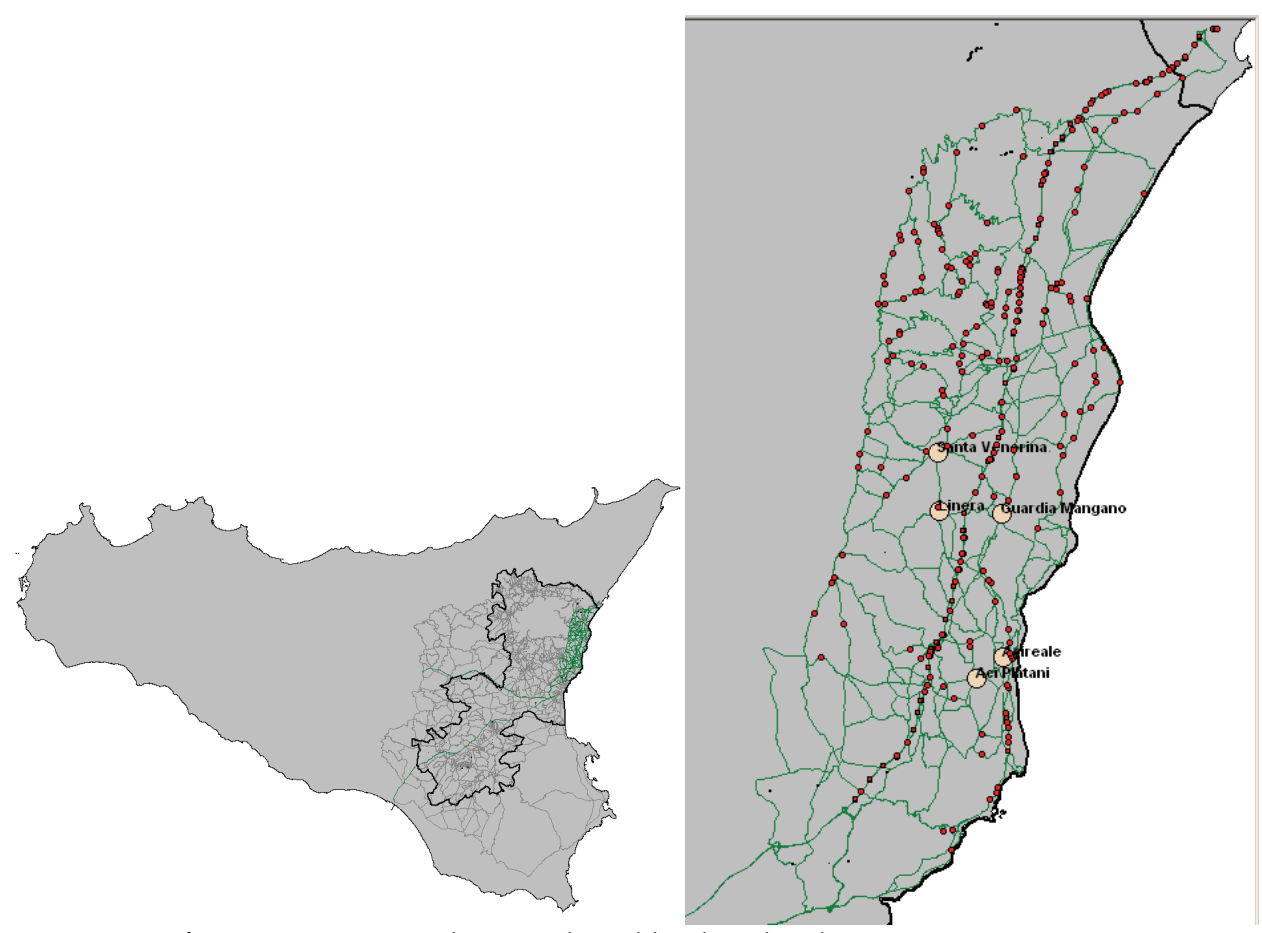

Fig. 5. Area of investigation, road network and bridges localization

Based on the history of seismic events in the investigated area, three levels of hazard (PGA values) were chosen, characterized by different return times:

1) events having a return time period of 50 years for the most frequent shakes (PGA with 50 $\%$ probability of exceeding the value in the next 50 years) (Figure 6.a);

2) events having a return time period of 100 years for not particularly severe and localized earthquakes (PGA with $39 \%$ probability of exceeding the value in the next 50 years) (Figure 6.b); 
3) events having a return time period of 475 years which corresponds to the strongest seismic events taken into consideration by building regulations (PGA with $10 \%$ probability of exceeding the value in the next 50 years) (Figure 6.c);

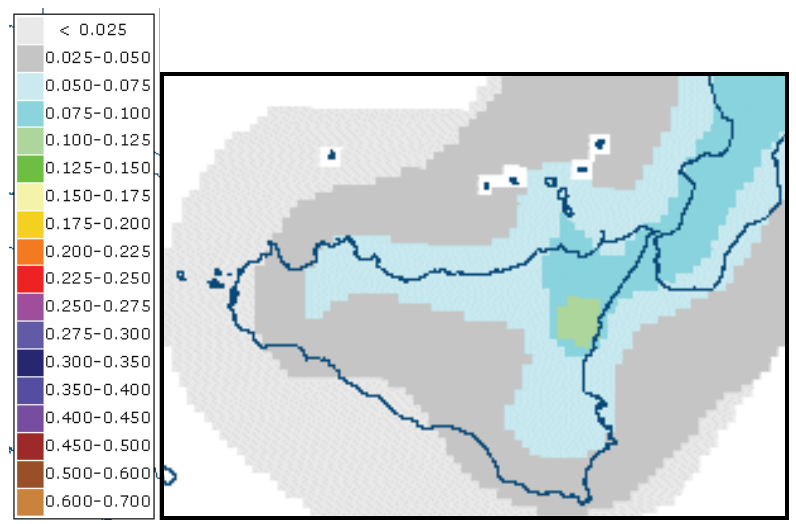

(a)

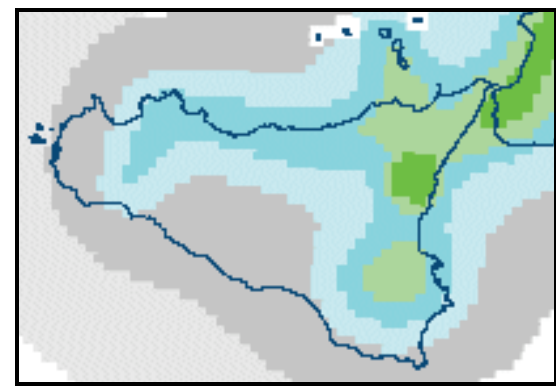

(b)

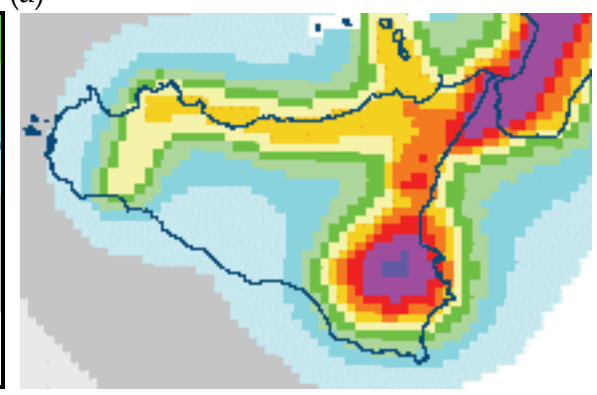

(c)

Fig. 6. Maps of PGA with return times of 50 years (a), 100 years (b) and 475 years (c) (Istituto Nazionale di Geofisica e Vulcanologia (I.N.G.V.), Italy)

\subsection{Risk assessment}

The methodology has been designed for applications based on Geographic Information System (GIS). The case study presentation is subdivided in four phases that represents the different activities carried out in the process to asses the seismic risk of the road network.

Phase 1 - damage and Loss of Transitability index

Using specific GIS tools, it was possible to attribute a specific PGA value to each bridge previously localized in the area (Figure 7) using an "overlay analysis" procedure on the area values drown from the seismic maps of I.N.G.V.. 


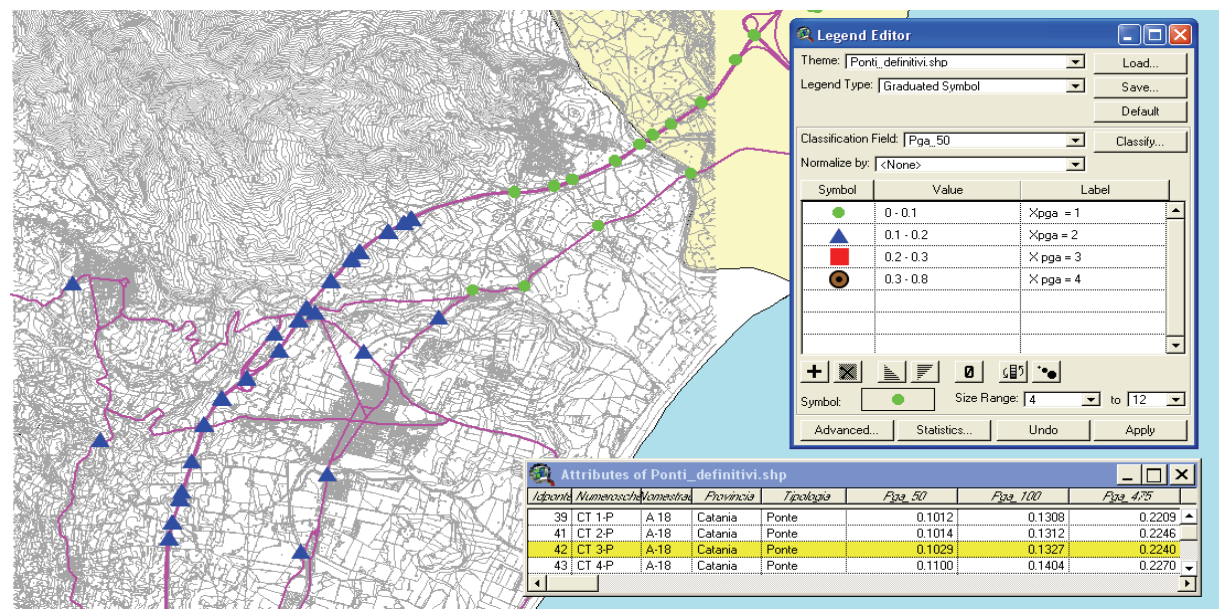

Fig. 7: 50, 100 and 475-year PGA maps of bridges on the road network

Once the vulnerability (Vj) was defined and the Hazard (XjPGA) noted, the adopted model made it possible to obtain the expected damage index for each bridge by means of the following relation:

$$
\mathrm{Dj}=\mathrm{XjPGA} \times \mathrm{Vj}
$$

From the relation showed in figure 4, also a value of Loss of Transitability can be associated as attribute to each bridge.

When dealing with stretches where there are no bridges or overpasses then both Damage and Loss of Transitability were taken as being equal to 0 for any earthquake scenario (50, 100 and 475 years). For those stretches where there is one bridge or overpass the Damage and Loss of Transitability indexes were assigned on the basis of values taken from the previously-illustrated model for the various earthquake scenarios at 50, 100 and 475 years (figure 5). Finally, if there is more than one bridge and/or overpass then the Damage and Loss of Transitability indexes of the stretch were considered as being equal to the maximum of the values attributed to the different bridges or overpasses.

Phase 2 - O/D routes

Two different emergency service origins were chosen:

1) Origin North $\left(\mathrm{O}_{\mathrm{N}}\right)$ : the motorway from the town of Messina that represent the connection of Sicilia Island to the continental part of Italy;

2) Origin West $\left(\mathrm{O}_{W}\right)$ : the interchange in the Catania urban Freeway, relating to emergency services coming from eastern Sicily and the southern part of the province of Catania.

As regards destinations, 5 towns in the study area were considered:

Acireale ( $D_{1}: 33,010$ inhabitants), Santa Venerina $\left(D_{2}: 4,056\right.$ inhabitants), Aciplatani $\left(\mathrm{D}_{3}\right.$ : 3,269 inhabitants), Linera ( $D_{5}: 2,781$ inhabitants), Guardia Mangano ( $\mathrm{D}_{6}: 2,457$ inhabitants).

The shape-file relating to the roads present in the province of Catania and the segmentation of the network as connected links makes it possible to use a GIS tool able to define the best route from the Origin $\left(\mathrm{O}_{N}\right.$ or $\left.\mathrm{O}_{W}\right)$ to the Destination $\left(\mathrm{D}_{\mathrm{i}}\right)$. The best rout is the one among all 
the alternatives which minimize the cost of transport obtained as sum of the cost attributes of each link composing the route (figure 8).

After having defined the origin (O) and the destination (D) in the earthquake scenario, 4 different routes can be identified for each O/D connection using as cost function Length, Time, Damage and Transitability attributes at 50, 100 and 475 years previously assigned to the links of the road network.
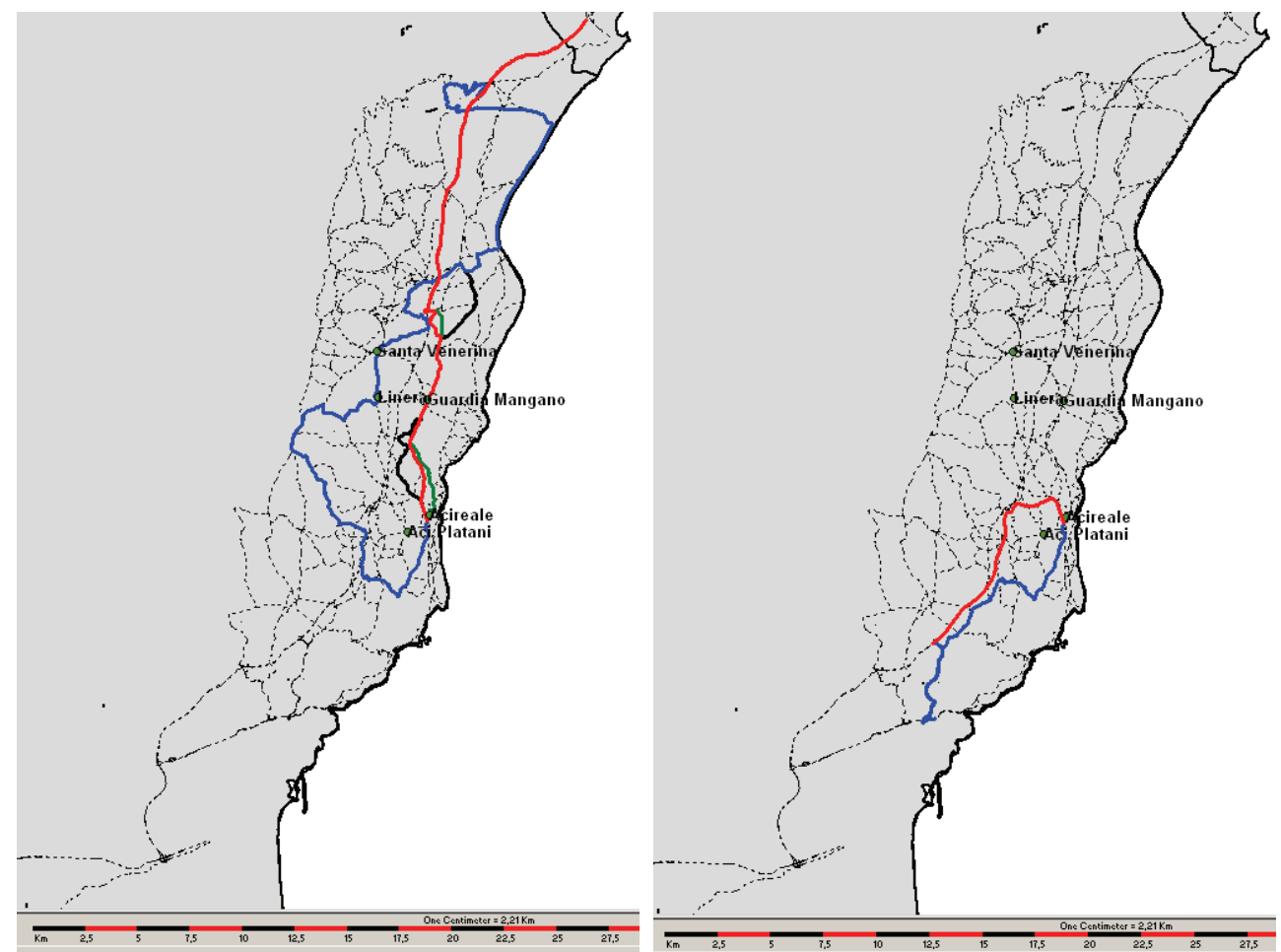

Fig. 8. Origin Nord and West: minimum length routes (red line), minimum time (green), minimum damage (blue) and minimum loss of transitability (black)

Phase 3 - Indirect exposure factor

An indirect exposure value is assigned to each link of the road network constituting part of the $\mathrm{O} / \mathrm{D}$ route equal to the number of inhabitants in the town of destination $\left(\mathrm{D}_{\mathrm{i}}\right)$ multiplied by its seismic risk index (exposure of the town).

Once all the O/Di routes of the same type has been identified for all the " $\mathrm{i}$ " destinations, an overall indirect exposure value can be associated to each link of the network equal to the sum of the values attributed to the link in each of the O/Di.

Therefore, some stretches of the network have a nil exposure, because they have never been used for O/D routes. Others have an exposure value based on a single destination, while those which have been used a number of times in order to reach different destinations have an exposure value equal to the sum of the exposures of the towns for which the stretch is used for that type of route (figure 9). 


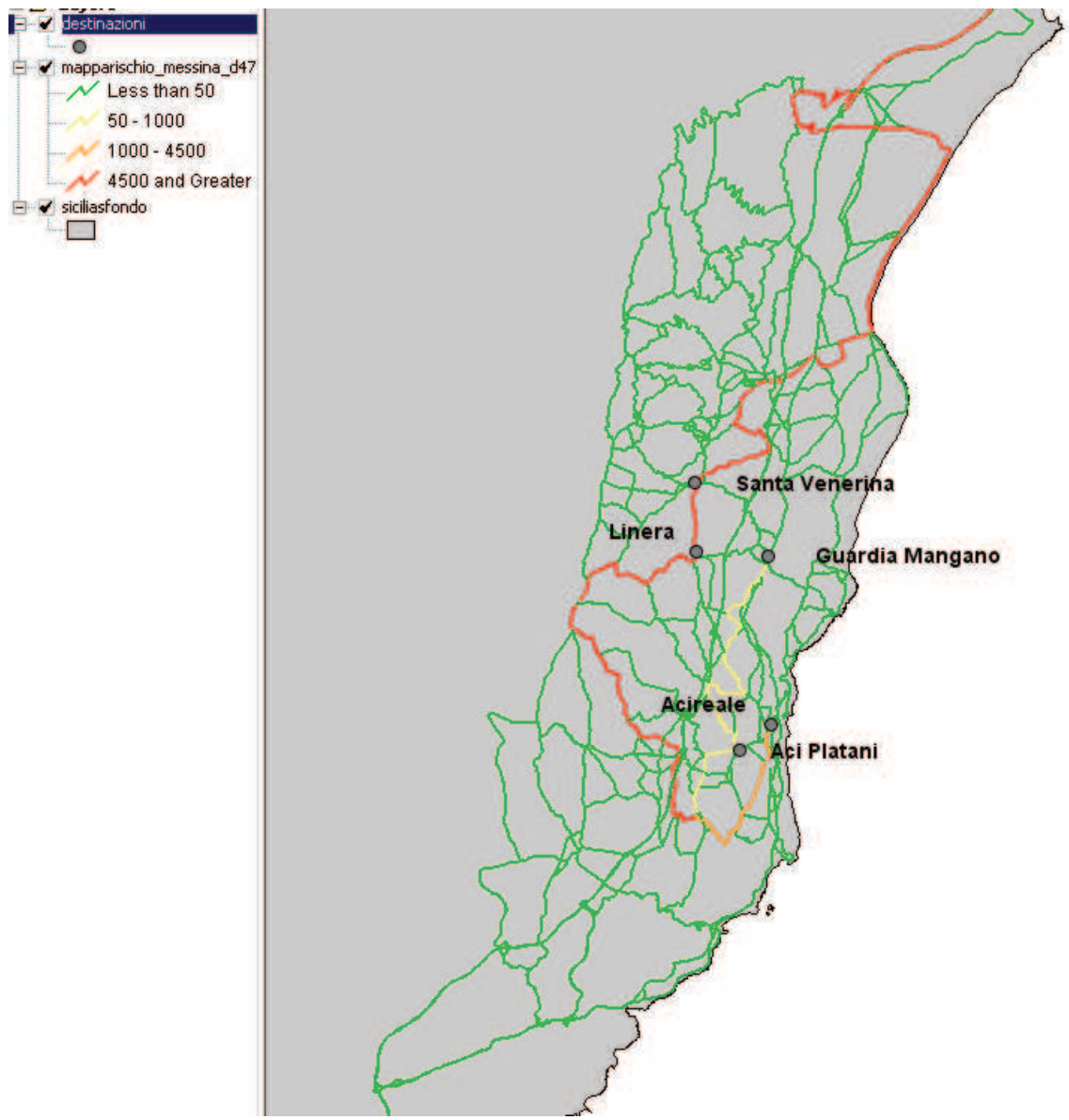

Fig. 9. classes of indirect exposure

Phase 4 - Risk evaluation of the links

When the damage value (Phase 2) and the indirect exposure of each single link of the network (Phase 3) are carried out it is possible to obtain the risk value relating to that particular route, by multiplying the damage value by the exposure value.

$$
\text { Risk }=\text { Indirect exposure } \times \text { Damage }
$$

In GIS environment, risk maps can be drawn up for each of the origins. The thematic maps graphically highlight those road network stretches having the highest risk index (Figures 10, 11) 


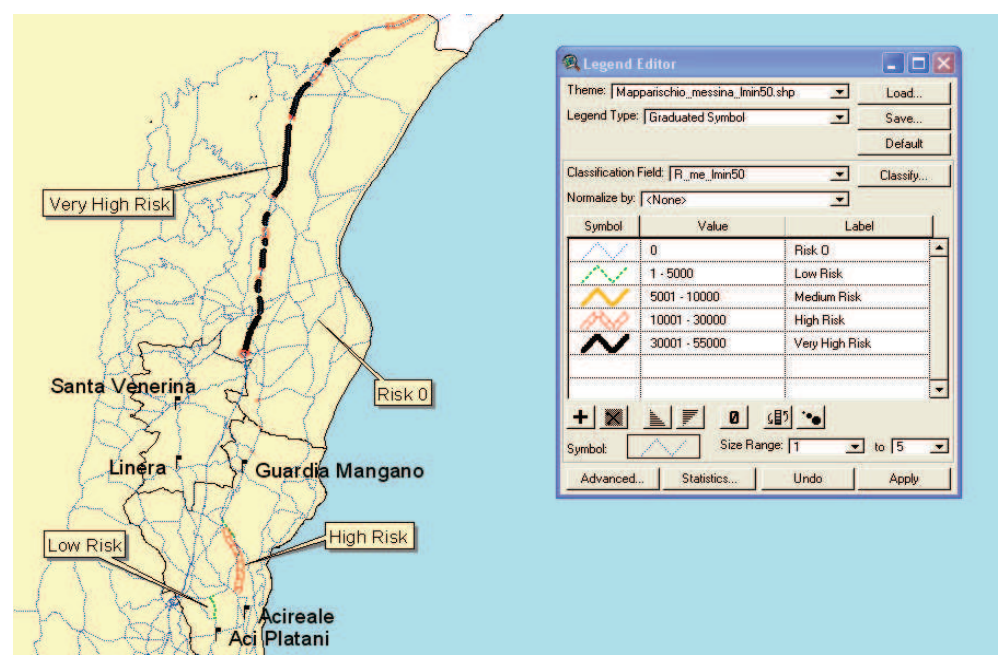

Fig. 10. Thematic risk map for the minimum length route (Cafiso et al, 2008)

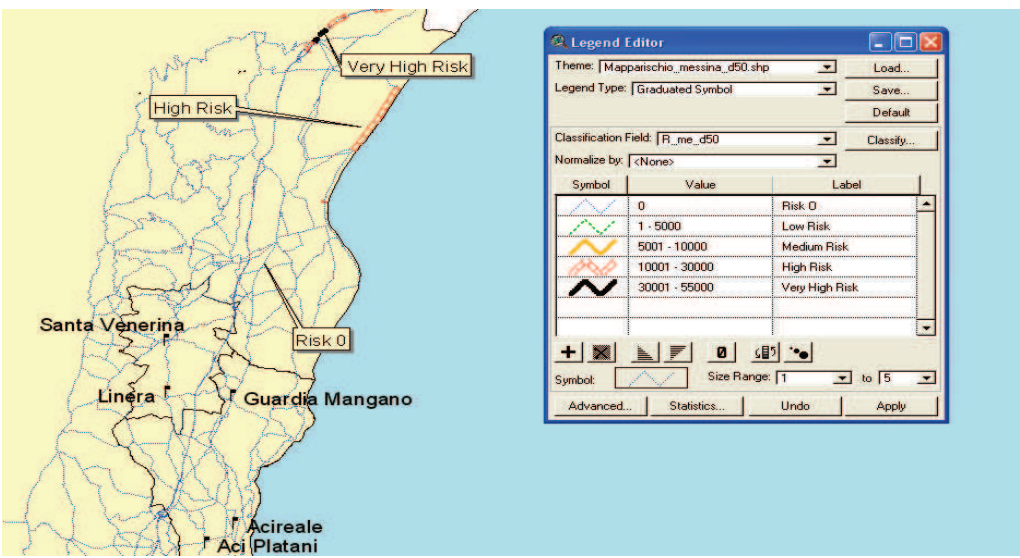

Fig. 11. Thematic risk map for the route with minimum damage (Cafiso et al, 2008)

\section{Lifeline Reliability}

In general terms, Reliability can be defined as the "the probability of a device performing its purpose adequately for the period of time intended under the operating conditions encountered" [1]. A road network, in particular, will be reliable if ".... provides a safe and not fluctuating service for the traffic and offers the users alternative routes, even when some parts of the system are not available due to road accidents, maintenance or natural disasters"

The transport network is affected by two different phenomena that can modify its reliability:

1) Variation in what is offered for transportation;

2) Variation in the demand on the transport services.

In the case of damage produced by seismic events the effects of the interruption of the local network and the consequence reduction in what remains available affect the overall 
performance of the system (increase in travel time, distance and costs). In some cases it could be of primary importance that the journey finishes in a determined period of time, while in other cases it is more important to evaluate if there are interruptions along the route that could obstruct to reach the destination [Selçuk, Yücemen, 1999 - Du, Nicholson, 1997).

With this aim the following two different terms of reliability can be defined:

- Terminal Reliability is "the probability that nodes are connected, i.e. it is possible to reach the destination" and this is surely the parameter that is easier to evaluate.

- Encountered Reliability is "the probability of not encountering a link degradation on the path with least (expected) cost".

Another concept that is complimentary to the previous, is the reliability of the time and cost of the journey, commonly defined as "the probability that a trip can be successfully finished within a specified time interval".

\subsection{Encountered Reliability}

For the attribution of an Encountered Reliability the travel-length and -time of the route from an origin $(\mathrm{Oj})$ to a destination $(\mathrm{Di})$ which minimize the overall cumulative expected damage after an earthquake (post event route) are compared with the original best route with the minimum travel time and length (travel cost) without considering any interruption (pre event route).

For each destination, the index of Encountered Reliability can be obtained by the formula [10]:

$$
E\left(O_{j}\right)_{R, D i}=\frac{l\left(O_{j}\right)_{\min , D i}{ }^{2}}{l\left(O_{j}\right)_{E \min , D i}{ }^{2}}
$$

where:

$\mathrm{Di}=$ Destination town for emergency services

$1(\mathrm{Oj}) \mathrm{min}, \mathrm{Di}=$ minimum cost (in terms of time or length) from the origin $(\mathrm{Oj})$ to the destination $\mathrm{Di}$ (pre event route);

$1(\mathrm{Oj})$ Emin, $\mathrm{Di}=$ travel cost (in terms of time or length) related to the route, from the origin (Oj) to the destination $\mathrm{Di}$, along which there are the minimum level of expected bridge damages (post event route).

Using this approach $\mathrm{E}(\mathrm{Oj})_{\mathrm{R}, \mathrm{Di}}$ is always less or equal to 1 and, therefore, the most reliable routes are characterized by higher values of $\mathrm{E}(\mathrm{O} \mathrm{j})_{\mathrm{R}, \mathrm{Di}}$ in as much as the alternative for the emergency services is not much longer than the direct route.

Once the values of $\mathrm{E}(\mathrm{Oj})_{\mathrm{R}, \mathrm{Di}}$ have been defined from equation (4) for each origin for the emergency services (Nord, West, etc.), it is possible to establish a general value for the Encountered Reliability for each town $\mathrm{ER}_{\mathrm{TOT}}(\mathrm{Di})$, as an average weighted on the itineraries with respect to the different origins:

$$
E_{R T O T(D i)}=\frac{\sum_{j} p_{j} E\left(O_{j}\right)_{R D i}}{\sum_{j} p_{j}}
$$

where: 
$\mathrm{O} \mathrm{j}=\mathrm{J}=1, . . \mathrm{n}$ and represents the $\mathrm{n}$ origins of the emergency services that can serve the destination Di;

$\mathrm{pj}=$ weight factor related to the importance of Origin $\mathrm{Oj}$;

From the relationship between the direct exposure values for each town (Di) and the relative total value of $\mathrm{E}_{\mathrm{RTOT}(\mathrm{Di})}$ it is possible to obtain an Encountered Risk factor RE(Di) related to each town (Destination) of the area under investigation (Figure 12):

$$
R E\left(D_{i}\right)=\frac{\text { Direct exposure }(\mathrm{Di})}{\mathrm{E}_{\mathrm{RTOT}, \mathrm{Di}}}
$$

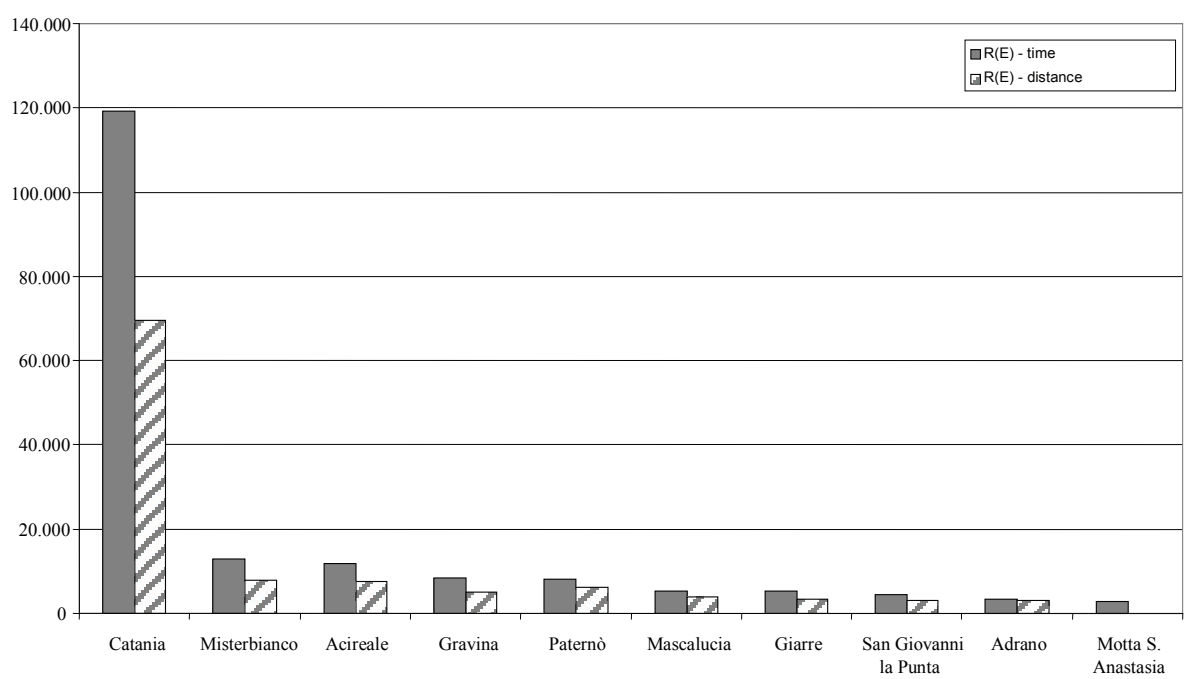

Fig. 4. Risk factors of Encountered Reliability related to different destinations (towns in East of Sicily, IT) (Cafiso et al., 2004)

\subsection{Terminal Reliability}

For the definition of Terminal Reliability the routes that lead, from the Origin (Oj), to the destination (Di), bypassing the bridges with defined level of damage are considered. The iterative procedure stops either when there are no more bridges to by pass along the alternative route and the destination is reached or it is no longer possible to reach the destination.

The index of Terminal Reliability, for the entire road network can be obtained by the formula:

$$
T\left(O_{j}\right)_{R, D i}=\frac{l\left(O_{j}\right)_{\min , D i}{ }^{2}}{l\left(O_{j}\right)_{T \min , D i}{ }^{2}}
$$

where:

$\mathrm{Di}=$ Destination town for emergency services 
$1(\mathrm{Oj}) \min , \mathrm{Di}=$ minimum cost (in terms of time or length) from the origin $(\mathrm{Oj})$ to the destination $\mathrm{Di}$ (pre event route);

$1(\mathrm{Oj}) \mathrm{Tmin}, \mathrm{Di}=$ travel cost (in terms of time or length) related to the route, from the origin (Oj) to the destination $\mathrm{Di}$, (post event route) along which there are only bridges with damage lower than a defined value.

Using this approach $\mathrm{T}(\mathrm{Oj})_{\mathrm{R}, \mathrm{Di}}$ is always less or equal to 1 and, therefore, the most reliable routes are characterized by higher values of $\mathrm{T}(\mathrm{Oj})_{\mathrm{R}, \mathrm{Di}}$.

Once the values of $\mathrm{T}(\mathrm{Oj}) \mathrm{R}$,Di have been defined from equation (7) for each origin for the emergency services (Nord, West, etc.), it is possible to establish a general value for the Terminal Reliability for each town $\mathrm{T}_{\mathrm{RTOT}}(\mathrm{Di})$, as an average weighted on the itineraries with respect to the different origins:

$$
T_{R T O T(D i)}=\frac{\sum_{j} p_{j} T\left(O_{j}\right)_{R D i}}{\sum_{j} p_{j}}
$$

where:

$\mathrm{O}=\mathrm{J}=1, . . \mathrm{n}$ and represents the $\mathrm{n}$ origins of the emergency services that can serve the destination Di;

$\mathrm{pj}=$ weight factor related to the importance of Origin $\mathrm{Oj}$;

From the relationship between the direct exposure values for each town (D) and the relative total value of $\mathrm{T}_{\mathrm{RTOT}, \mathrm{Di}}$ it is possible to obtain the risk factor $\mathrm{R}$ (Figure 13):

$$
R T\left(D_{i}\right)=\frac{\text { Direct exposure }\left(\mathrm{D}_{\mathrm{i}}\right)}{\mathrm{T}_{\mathrm{RTOT}, \mathrm{Di}}}
$$

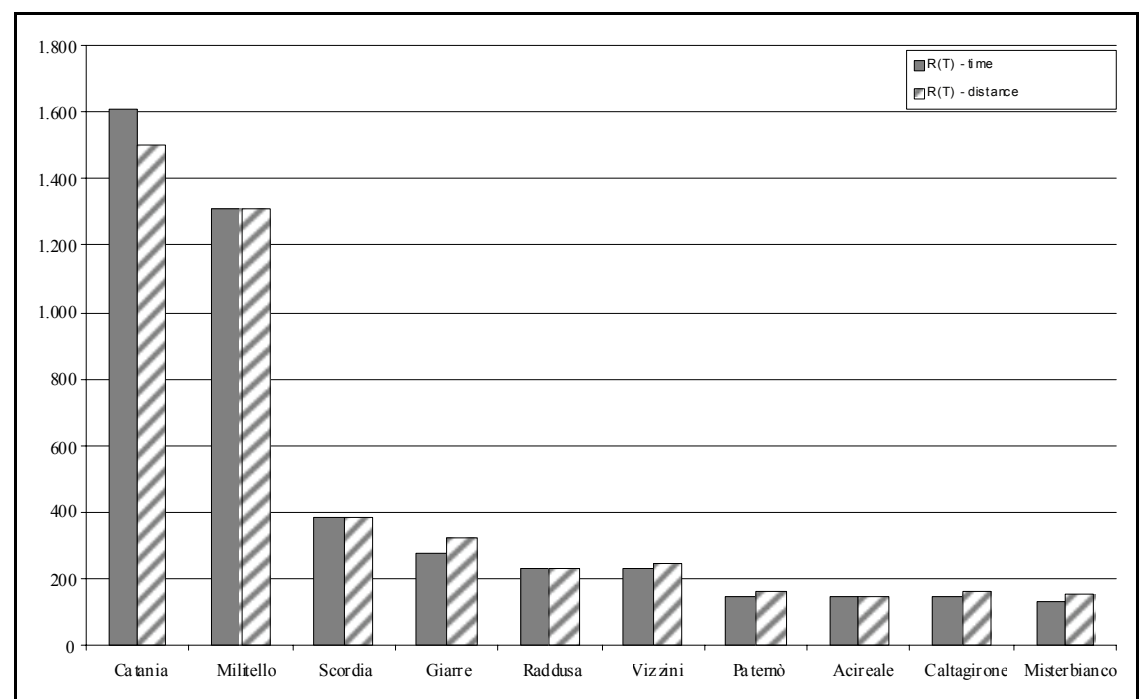

Fig. 13. Risk factors connected to Terminal Reliability (Cafiso et al., 2004) 
If the previous definition of Risk (paragraph 3) is associated to the network links, Encountered and Terminal Reliability Risk factors are related to the town of destination given an evaluation of the probability to encounter an obstruction in the route to reach the destination.

\section{Conclusions}

The maintenance of an efficient road network after an earthquake is fundamental if emergency services from outside the area have to reach the struck towns as easily and quickly as possible. Therefore, risk and reliability assessment of road network are indispensable to evaluated beforehand, so as to program seismic retrofitting works to the links which are strategic to the efficient functioning of the road network.

An original methodology to conduct risk assessment is presented, which makes it possible to identify the links of the road network with a higher level of risk both as regards to possible structural damage and the importance of the connection related to the number of inhabitants that can be reached by the emergency services. The analyses were carried out considering bridges as the "weak" element of the road infrastructure in cases of seismic events, but the procedure could also be applied to different types of element (trenches, embankments, culverts, etc).

Using a high seismic-risk area of eastern Sicily as a case study, it was possible to verify the effectiveness of the proposed procedure. In particular, implementing the method using a GIS software made it possible to draw up maps which identify the most critical stretches for different earthquake scenarios (return times of 50, 100, 475 years) and emergency service origins.

Also the concepts of Encountered and Terminal Reliability can be used to identify the routes that lead to specific destination from the origins of emergency services, crossing the minimum level of expected damage of bridges, both in terms of length and time to cover the given distance. These values can be referred to the towns of destination for the emergency services allowing the definition of a risk index relative to the accessibility of the town in case of earthquakes.

If the previous definition of Risk (paragraph 3) is associated to the network links, Encountered and Terminal Reliability Risk factors are related to the town of destination given an evaluation of the probability to encounter an obstruction in the route to reach the destination.

This information are useful in order to identify those parts of the road network where more resources should be employed both to program retrofitting work on structures and for a more in-depth analysis of the system.

\section{References}

Buckle I.G., Kim S.H., A vulnerability assesment for highway bridge. ASCE. Lifeline Earthquake Engineering, 1995.

Cafiso S., Condorelli A., Cutrona G., Mussumeci G. A Seismic Network Reliability Evaluation on GIS Environment - A Case Study on Catania Province. Risk Analysis IV, 2004, pagg. 131-140 - WIT Press, - ISBN 1-85312-736-1. 
Cafiso S., Condorelli A., D'Andrea A.. Methodological Considerations for the Evaluation of Seismic Risk on Road Network. Pure and Applied Geophysics, Vol. 162, n. 4, 2005. pagg.767-782.

Cafiso S., La Bruna A., La Cava G. "Seismic Risk Assessment of Rural Road Network". Risk Analysis, Simulation and Hazard Mitigation V. pp.91-100. WITpress, Southampton, United Kingdom, 2008. ISBN: 978-1-84564-104-7.

Cafiso S. "Seismic Risk and Reliability for Rural Road Network". IASTED International Conference on Modelling, Simulation and Identification, 2009, Pechino, Cina.

Du Z.P., Nicholson A.J., Degradable Transportation System: Sensitivity and Reliability Analysis, Transportation Research B, 31(3), 225-237, 1997.

Istituto Nazionale di Geofisica e Vulcanologia (I.N.G.V.). Mappa di pericolosità sismica del territorio nazionale PCM n. 3519, All. 1b. April 2006 in http:/ / zonesismiche.mi.ingv.it/

Ord.P.C.M. n. 2788 del 12/06/1998, Individuazione delle zone ad elevato rischio sismico del territorio nazionale, 1998.

NCHRP REPORT 525 - Costing Asset Protection: An All Hazards Guide for Transportation Agencies (CAPTA), Vol. 15, ISBN 978-0-309-11763-0, TRB 2009

Selçuk A.S., Yücemen M.S., Reliability of lifeline networks under seismic hazard. Reliability Engineering and System Safety, pp. 213-227, 1999

Wakabayashi H., Idia Y., Upper and Lower bounds of terminal reliability of road networks: an efficient method with Boolean Algebra. Journal of Natural Disaster Science 14, pp. 29-44, 1992. 


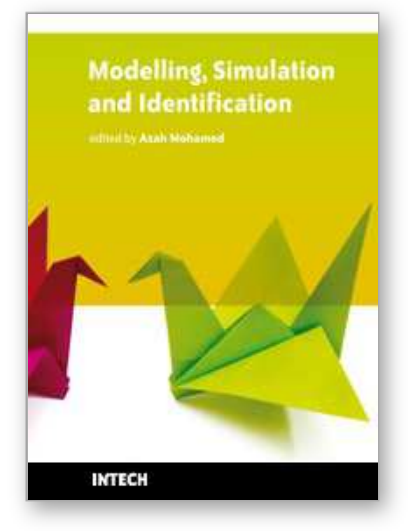

\author{
Modelling, Simulation and Identification \\ Edited by Azah Mohamed
}

ISBN 978-953-307-136-7

Hard cover, 354 pages

Publisher Sciyo

Published online 18, August, 2010

Published in print edition August, 2010

Modeling, simulation and identification has been actively researched in solving practical engineering problems. This book presents the wide applications of modeling, simulation and identification in the fields of electrical engineering, mechanical engineering, civil engineering, computer science and information technology. The book consists of 17 chapters arranged in an order reflecting multidimensionality of applications related to power system, wireless communication, image and video processing, control systems, robotics, soil mechanics, road engineering, mechanical structures and workforce capacity planning. New techniques in signal processing, adaptive control, non-linear system identification, multi-agent simulation, eigenvalue analysis, risk assessment, modeling of dynamic systems, finite difference time domain modeling and visual feedback are also presented. We hope that readers will find the book useful and inspiring by examining the recent developments in the applications of modeling, simulation and identification.

\title{
How to reference
}

In order to correctly reference this scholarly work, feel free to copy and paste the following:

Salvatore Cafiso (2010). Assessment of Seismic Risk and Reliability of Road Network, Modelling, Simulation and Identification, Azah Mohamed (Ed.), ISBN: 978-953-307-136-7, InTech, Available from:

http://www.intechopen.com/books/modelling--simulation-and-identification/seismic-risk-assessment-of-roadnetwork

\section{INTECH}

open science | open minds

\author{
InTech Europe \\ University Campus STeP Ri \\ Slavka Krautzeka 83/A \\ 51000 Rijeka, Croatia \\ Phone: +385 (51) 770447 \\ Fax: +385 (51) 686166 \\ www.intechopen.com
}

\author{
InTech China \\ Unit 405, Office Block, Hotel Equatorial Shanghai \\ No.65, Yan An Road (West), Shanghai, 200040, China \\ 中国上海市延安西路65号上海国际贵都大饭店办公楼405单元 \\ Phone: +86-21-62489820 \\ Fax: +86-21-62489821
}


(C) 2010 The Author(s). Licensee IntechOpen. This chapter is distributed under the terms of the Creative Commons Attribution-NonCommercialShareAlike-3.0 License, which permits use, distribution and reproduction for non-commercial purposes, provided the original is properly cited and derivative works building on this content are distributed under the same license. 